\title{
sciendo
}

ISSN: $1231-4005$

e-ISSN: $2354-0133$

DOI: $10.2478 /$ kones-2019-0085

\section{SLIP AT VEHICLE TRANSMISSION SYSTEM WITH HYDROKINETIC CONVERTER IN THE URBAN TEST CYCLE}

\author{
Andrzej Bieniek, Jarosław Mamala, Krzysztof Prażnowski, Mariusz Graba \\ Opole University of Technology \\ Faculty of Mechanical Engineering \\ Mikołajczyka Street 5, 45-271 Opole, Poland \\ tel.: +48774498447, +48774498437, +48774498443, +48774498446 \\ e-mail:a.bieniek@po.edu.pl,j.mamala@po.edu.pl \\ k.praznowski@po.edu.pl,m.graba@po.edu.pl
}

\begin{abstract}
The study concentrated on slip phenomenon occurring at hydrokinetic converter in passenger car transmission system. Optimization of modern automatic transmission systems aims, on the one hand, to further increase the comfort of use, and on the other hand to improve the efficiency and reliability operation of individual components, in such a way as to ultimately result in lowering fuel consumption and also harmful emissions. One of the important factors affecting the mentioned transmissions properties as a whole system is the slip phenomenon occurring between the pump and the hydrokinetic converter turbine. The study presents the results of research on ZF $4 H P 20$ and Fuji Hyper M6 gearboxes operating in vehicle transmission systems. The tests were carried out using the MAHA MSR 500 chassis dynamometer during driving at chosen test cycles. The research covered the transmission systems operating according to selected control algorithms affecting not only the gear shifting strategy but also the operation of the lock up clutch causing the transmissions slip values. As shown by the conducted research, the algorithm controlling the operation of the torque converter can have a significant influence on their operating indexes. The conducted analyses indicate the possibilities of improving the transmission operating indexes, especially in urban driving cycles.
\end{abstract}

Keywords: hydrokinetic transmission, transmission slip, test cycle, chassis dynamometer

\section{Introduction}

Vehicle manufacturers are continuously improving their designs of drivetrain components. Aside from large spending on research and development related to engines, vehicle manufacturers also spend substantial amounts of time and funds on vehicle drivetrains to improve their performance indicators. There are numerous drivetrain designs available on the market. The following transmission designs can be differentiated: Manual transmissions (MT), automatic transmissions equipped with a hydraulic torque converter (AT), continuously variable transmissions (CVT), automated transmissions (AMT) and double clutch transmissions (DCT), where gear shifting can be either automated or manual. The global market share of automated and automatic transmissions exceeds $50 \%$, as can be seen in Fig. 1. A decreasing customer interest in manual transmissions can also be observed. The market share of classic automatic transmissions (AT) is declining; however, it is still significant on a global scale, exceeding $30 \%$. A hydrokinetic torque converter used in automatic transmissions to connect the engine with mechanical planetary gearing of the gearbox is also commonly used in numerous CVT designs for torque transmission from the engine.

Concurrently, a trend of increasing the number of gears can be seen, resulting in increased gear range. A considerable number of available gears $(8-10)$ are most common in case of automatic transmissions (AT) with a hydrokinetic torque converter.

An increased gear number (and therefore increased gear range) results in possibilities of utilizing a wider range of the available engine characteristic, especially in case of currently dominant internal 
combustion (IC) engines. Steptronic, S-Tronic transmissions can be given as examples of available automatic gearboxes with 7 or 8 gears. In recent years, 9-gear designs (9G-tronic) or 10-gears designs (Ford 10R80, GM 10LXX) have become available. An increased gear range can lower fuel consumption by as much as $3-4 \%$, in relation to manual transmissions.

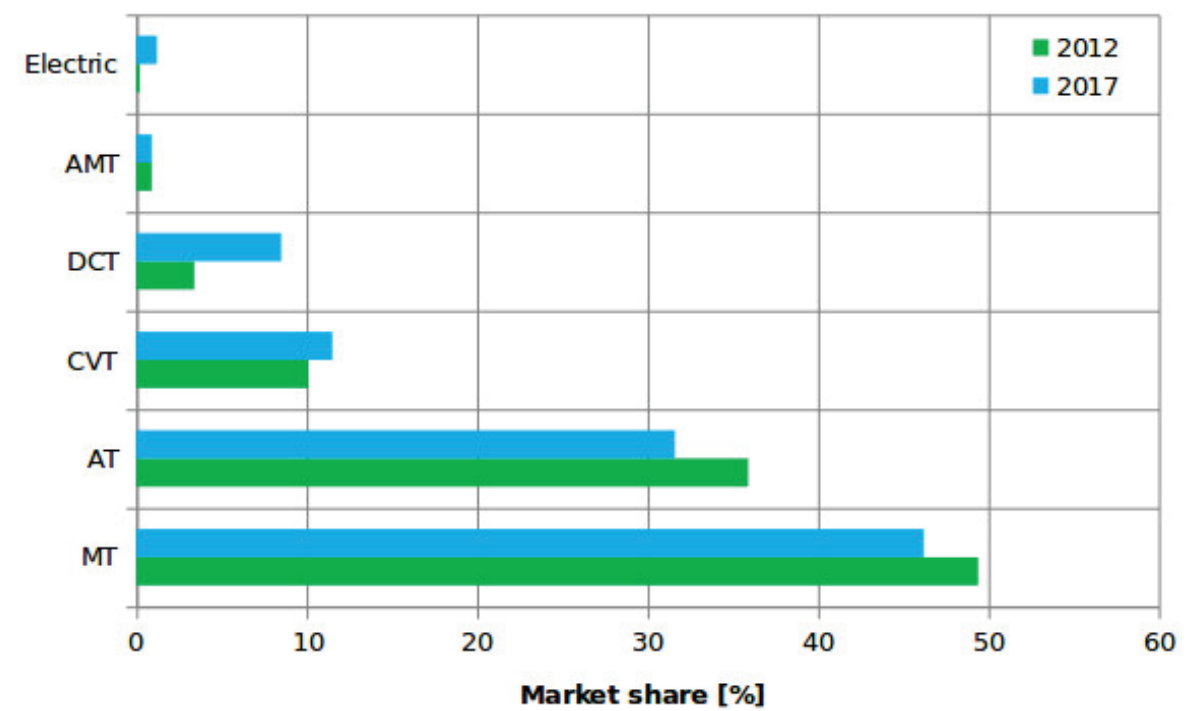

Fig. 1. Global market share of transmission types: Electric - transmissions for electric vehicles (usually single-speed transmissions), AMT-Automated Manual Transmissions, DCT-Double Clutch Transmission, CVT-Continuously Variable Transmission, AT-Automatic Transmission, MT-Manual Transmission [11]

\section{Hydrokinetic Transmission operating conditions}

The utilization of a large number of gears in modern hydrokinetic transmissions allows for an increase in gear range, which in turns allows engine operation near its optimum operating range [4]. However, it has to be taken into consideration that there is still need for a mechanism that transfers the torque between the engine and transmission, allowing to get the vehicle in motion and to travel at low speeds. Operation of this element - in most cases, the hydrokinetic converter is associated with losses in the drivetrain. They are the effect of slip that occurs between the main elements of the converter, i.e. the pump and the turbine. As the slip decreases, drivetrain efficiency increases.

In his work [10], Ejiri has showcased the characteristics of efficiency $\eta$, torque ratio $\mu$ and torque capacity coefficient $\tau$, taking into account the locking of pump-turbine movement with the use of a lock-up clutch. Engagement of the lock-up mechanism results in a significant increase of hydrokinetic transmission efficiency, as its value nears the $100 \%$ mark.

Asl, Azad and McPhee have presented research related to modelling torque conversion by the hydrokinetic converter equipped with a lock-up clutch. Simulation results have shown that the lock-up clutch significantly improves hydrokinetic transmission efficiency [8] and different control strategies of lock-up clutch have significant impact on transmission slip profile $[1,5]$.

In earlier hydromechanical transmission designs, the lock-up clutch was engaged only in $3^{\text {rd }}$ and $4^{\text {th }}$ gear. In current designs, the lock-up clutch is engaged in every gear, and the turbine and impeller are locked by it in the range of engine speeds encompassing 1100-1700 rpm. In modern designs, the lock-up clutch operates continuous partial slip, which is modulated. This results in the converter operating in completely locked mode or with minimal slip, therefore shortening the phase during which the converter operates at full opening [6, 7]. The process of controlling lockup clutch was modelled and mathematically described by Koralewski and Wrona [9].

In case of automotive transmissions with CVT advanced control, strategies of their frictional conditions and shifting could also improve operating indexes [2-4]. 


\section{Experimental setup}

Two vehicles equipped with hydrokinetic converters were subjected to experimental tests in this research:

- Citroen C5 3.0 V6 Automatic with a hydromechanical gearbox, ZF 4HP20 type,

- Fiat Punto with a Fuji Hyper M6 CVT transmission coupled with a hydrokinetic converter.

Selected parameters of tested transmissions are shown in Tab. 1.

For the Citroen C5 vehicle, the electronic transmission control with an implemented adaptive function (DSP - Dynamisches Schalt Program) was used. The driver can choose four modes of operation for this type of electronic control:

D - program focusing on best possible fuel economy,

$\mathrm{S}$ - program focusing on best possible vehicle dynamics - sport driving,

D* - program for driving in reduced road grip conditions,

Seq - program allowing for sequential gear shifting by the driver.

The second research object - a Fiat Punto passenger vehicle, was equipped with a CVT transmission, which employs a hydrokinetic torque converter for torque transfer from the engine to the transmission. The hydrokinetic converter is electronically operated, taking into account a number of signals, such as throttle position, engine speed or engine load. The driver can choose one of the four following transmission operation programs:

D - a compromise between dynamic and fuel-efficient driving,

DE - program focusing on best possible fuel economy,

L - program focusing on best driving dynamics and driving under heavy engine load,

Seq - program allowing for sequential gear shifting by the driver (simulated gear ratios).

The experimental research was conducted at Opole University of Technology with the use of the MAHA MSR 500 chassis dynamometer. One of the main parameters registered during tests was the pump-turbine slip of the hydrokinetic converter, calculated with the use of Equation (1).

$$
s=\frac{\left(n_{\text {in }}-n_{\text {out }}\right)}{n_{\text {in }}} \cdot 100 \%,
$$

Where:

$n_{\text {in }}$ - pump rotational speed, $\mathrm{rpm}$,

$n_{\text {out }}$ - turbine rotational speed, rpm.

Pump and turbine rotational speeds were registered with the use of active sensors installed on the transmission, which operated at a resolution of 60 impulses per rotation.

Test cycles mirroring urban driving conditions were conducted to investigate the effect of transmission control programs on converter slip, as shown in Fig. 2, whereas analysis of obtained results was performed basing on a test that was repeated twice.

Concurrently, transmission load was imposed on the drivetrain in accordance with Equation (2) representing the power on vehicle has driven wheels:

$$
P=\left(m g f_{t}+\frac{\rho}{2} c_{x} A v^{2}+m a\right) v .
$$

Load parameters for test vehicles: Citroen C5 and Fiat Punto are shown in Tab. 1, respectively.

Courses of wheel load (and therefore transmission load) in time obtained by imposing the previously calculated forces on the vehicle drivetrain with the use of a chassis dynamometer are shown in Fig. 2.

Similar wheel load power courses were obtained for both tests subjects. There are some visible discrepancies resulting from imposed load parameters, which accounted for vehicle chassis and wheel characteristics. Negative values visible in Fig. 5, should be interpreted as the effect of engine braking, resulting in power flow from the wheels to the engine. 
Tab. 1. Force resistance load parameter for Citroen C5 and Fiat Punto

\begin{tabular}{|c|c|l|c|c|c|}
\hline No. & Symbol & \multicolumn{1}{|c|}{ Designation } & Value (Citroen C5) & Value (Fiat Punto) & Unit \\
\hline 1. & $m$ & Vehicle mass & 1495 & 1150 & $\mathrm{~kg}$ \\
\hline 2. & $g$ & Gravity acceleration & 9.81 & 9.81 & $\mathrm{~m} \cdot \mathrm{s}^{2}$ \\
\hline 3. & $f_{t}$ & Rolling resistant coefficient & 0.010 & 0.010 & - \\
\hline 4. & $\rho$ & Air density & 1.204 & 1.204 & $\mathrm{~kg} \cdot \mathrm{m}^{-3}$ \\
\hline 5. & $c_{x}$ & Air resistant coefficient & 0.290 & 0.320 & - \\
\hline 6. & $A$ & Vehicle frontal area & 2.250 & 2.120 & $\mathrm{~m}^{2}$ \\
\hline 7. & $v$ & Vehicle speed & speed profile & speed profile & $\mathrm{m} \cdot \mathrm{s}^{-1}$ \\
\hline 8. & $a$ & Vehicle acceleration & speed profile & speed profile & $\mathrm{m} \cdot \mathrm{s}^{-2}$ \\
\hline
\end{tabular}

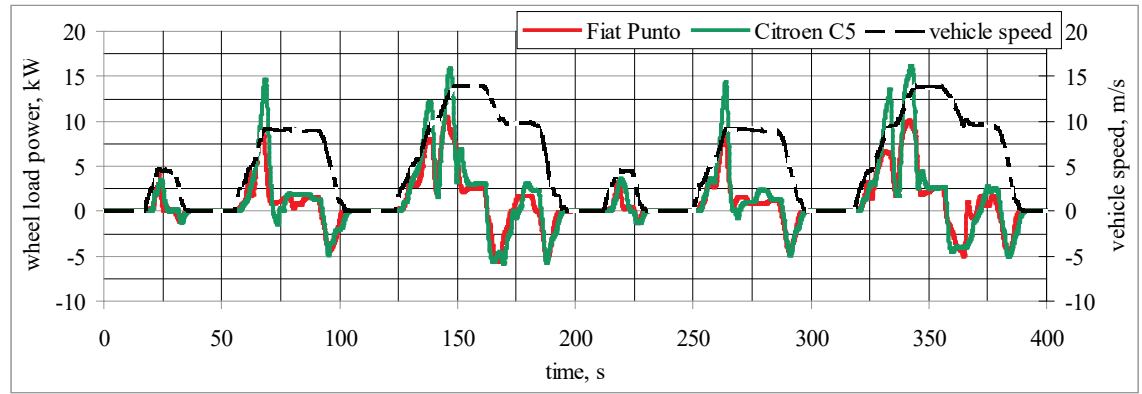

Fig. 2. Realization of Urban test cycle: vehicle speed profile, wheel load power for Fiat Punto and Citroen C5

\section{Experimental results}

Test driving cycles were performed to determine the effect of chosen transmission operation program on converter slip in urban conditions. Examples of registered slip vs. time courses are shown in Fig. 3 for Citroen C5 and in Fig. 4 for Fiat Punto.

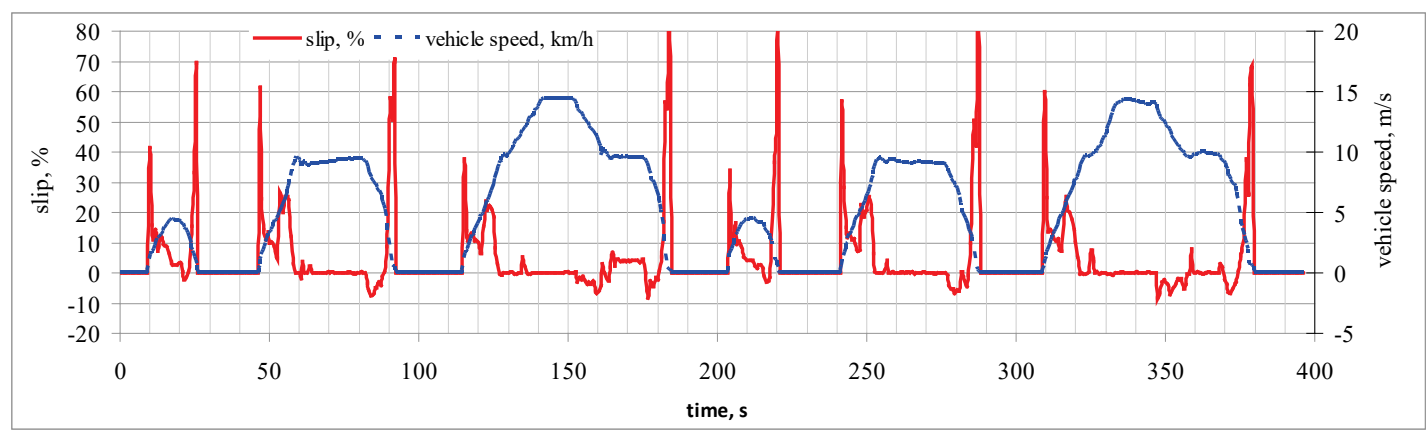

Fig. 3. Transmission slip at test cycle for Citroen C5

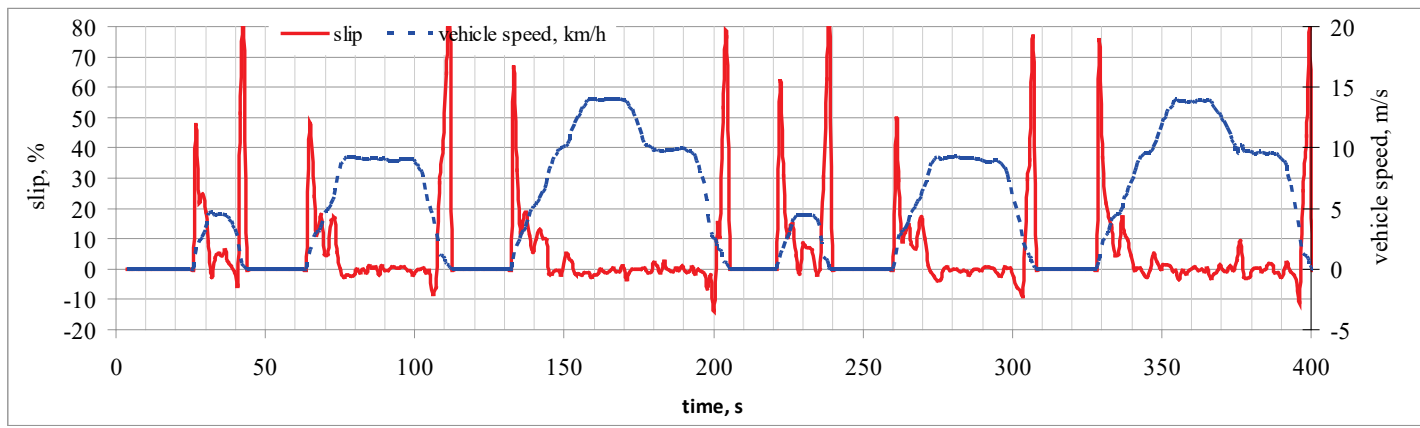

Fig. 4. Transmission slip at test cycle for Fiat Punto 
As can be seen in Figs. 3 and 4, the largest values of slip can be observed at low vehicle speeds. Above a certain speed threshold (depending on the control program), the slip decreases. This is related to the engagement of a lock-up clutch.

To showcase the effect of control program and vehicle speed on converter slip, research results were presented in subsequent graphs. The effect of used control programs $\left(\mathrm{D}, \mathrm{D}^{*}, \mathrm{~S}\right)$ and sequential gear change by the driver for Citroen C5 test vehicle is shown in Figs. 5-8. Presentation of converter slip depending on vehicle speed allows observing the range of slip disappearance. In case of Citroen C5 test vehicle, a substantial effect of control program on converter slip can be seen. For the D program, significant slip can be observed as far as above the speed of $10 \mathrm{~m} / \mathrm{s}$ (Fig. 5), whereas for the S program, a significant reduction in slip can be seen in the range of $5-7 \mathrm{~m} / \mathrm{s}$, with slip pretty much disappearing after reaching $8 \mathrm{~m} / \mathrm{s}$ (Fig. 7).

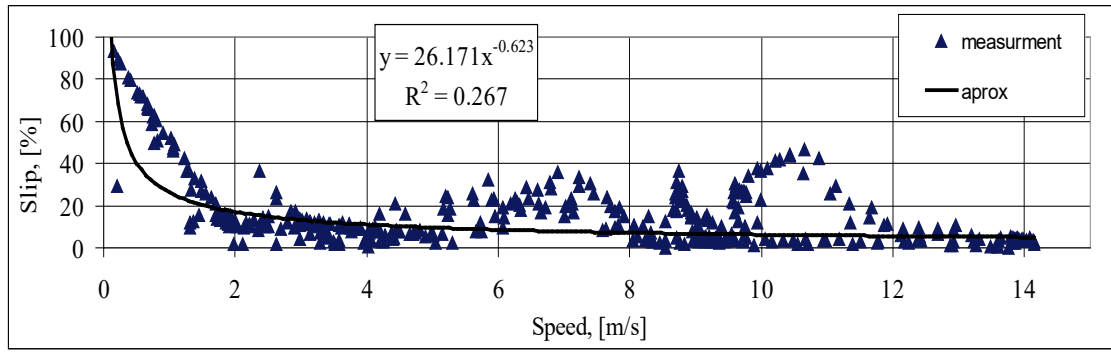

Fig. 5. Transmission slip at program D (Citroen C5)

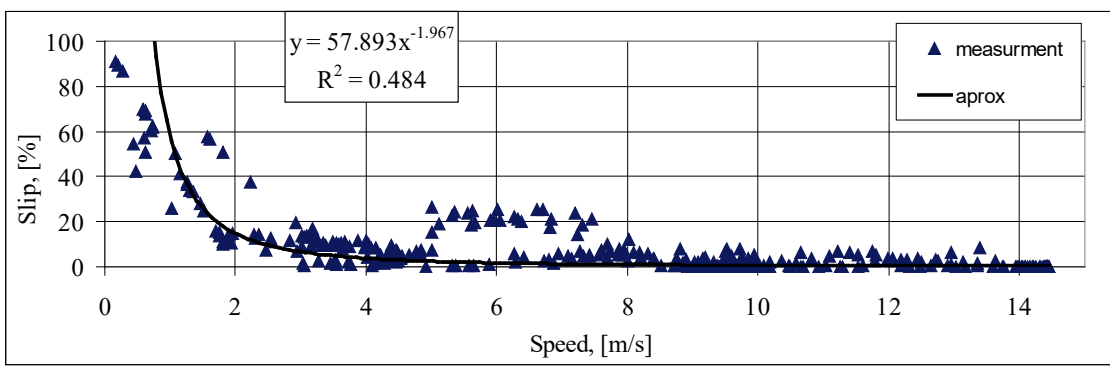

Fig. 6. Transmission slip at program D* (Citroen C5)

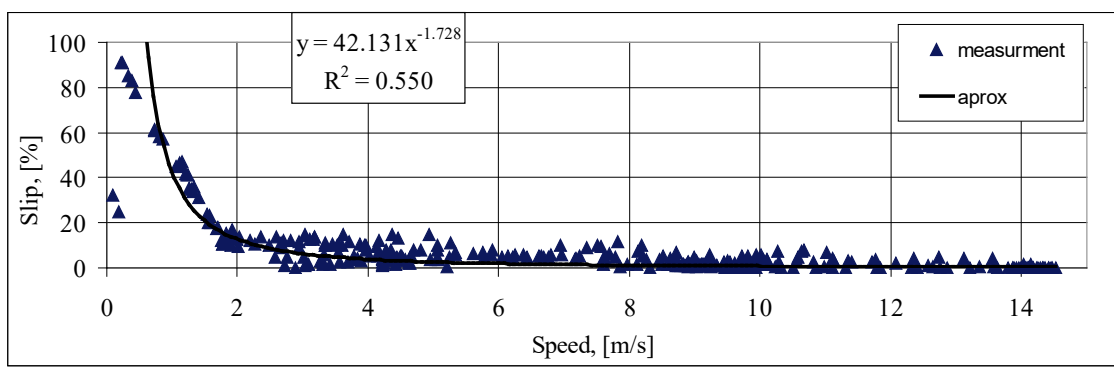

Fig. 7. Transmission slip at program S (Citroen C5)

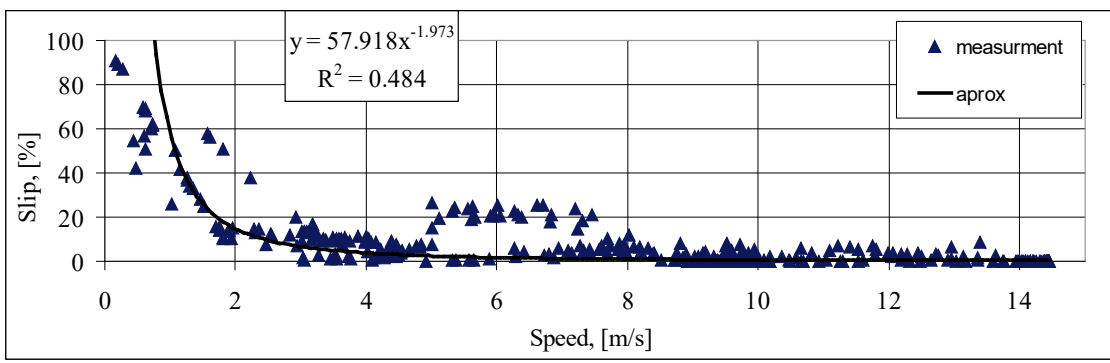

Fig. 8. Transmission slip at sequential ratio change by driver (Citroen C5) 
Using the $\mathrm{D}^{*}$ program and sequential gear change result in limited slip in comparison to the basic D program in the range of $0-12 \mathrm{~m} / \mathrm{s}$ vehicle speeds.

The effects of used control program and vehicle speed in case of Fiat Punto test vehicle are shown in Figs. 9-12.

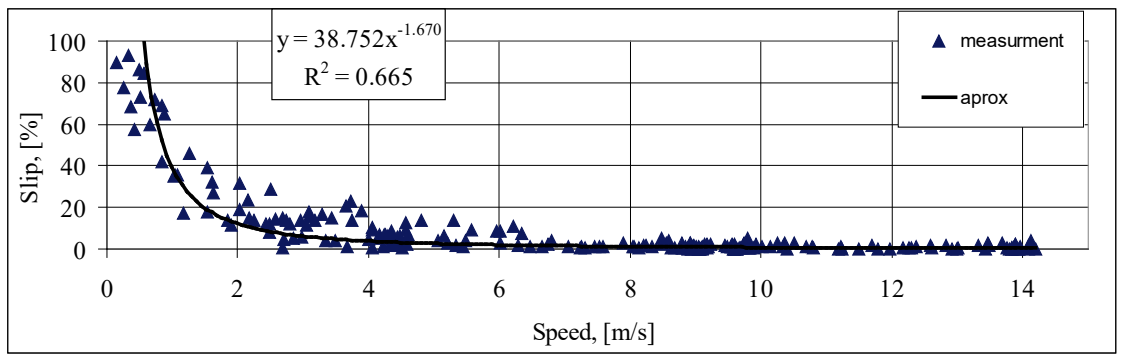

Fig. 9. Transmission slip at program D (Fiat Punto)

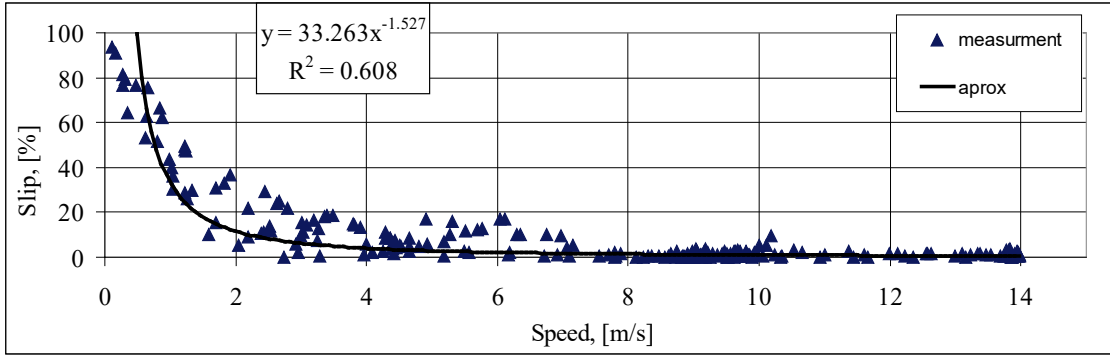

Fig. 10. Transmission slip at program DE (Fiat Punto)

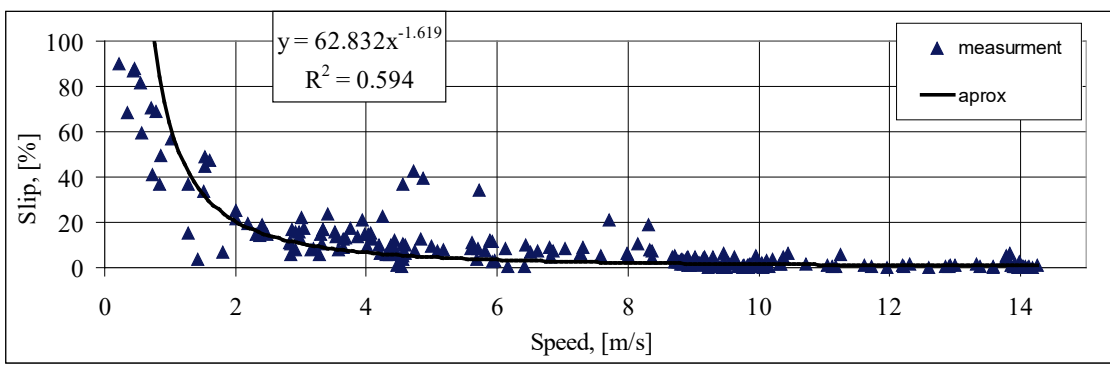

Fig. 11. Transmission slip at program L (Fiat Punto)

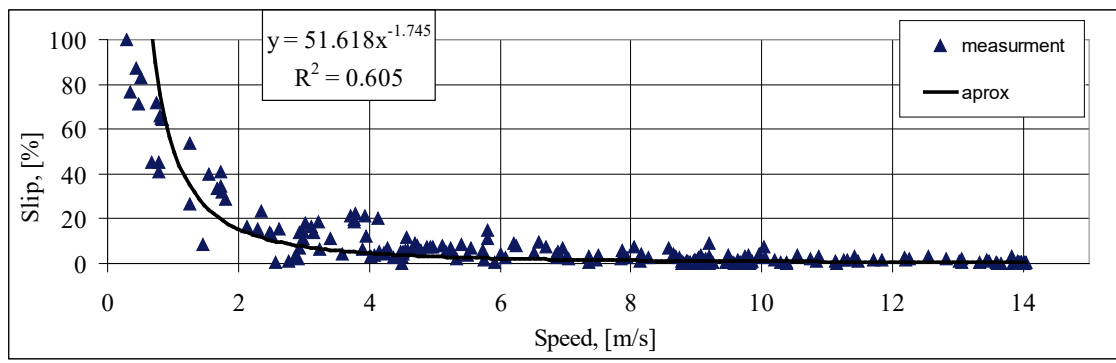

Fig. 12. Transmission slip at sequential ratio change by driver (Fiat Punto)

Analysis of presented graphs shows that use of the D control program results in relatively low converter slip values and its near-disappearance above the speed of $6 \mathrm{~m} / \mathrm{s}$. Driving with the use of DE and L programs extends the range of speeds at which slip occurs to approximately $7 \mathrm{~m} / \mathrm{s}$ and $9 \mathrm{~m} / \mathrm{s}$, respectively.

After the analysis of the entire driving cycle, mean hydrokinetic slip value was calculated using Equation (3), basing on obtained transmission slip curves in time $S(t)$. 


$$
\bar{s}=\frac{\int_{0}^{t} S(t)}{t},
$$

where:

$t \quad$ - time, $\mathrm{s}$,

$S(t)$ - transmission slip curve.

Mean values of transmission slip in test cycles for different control program are shown in Fig. 13.

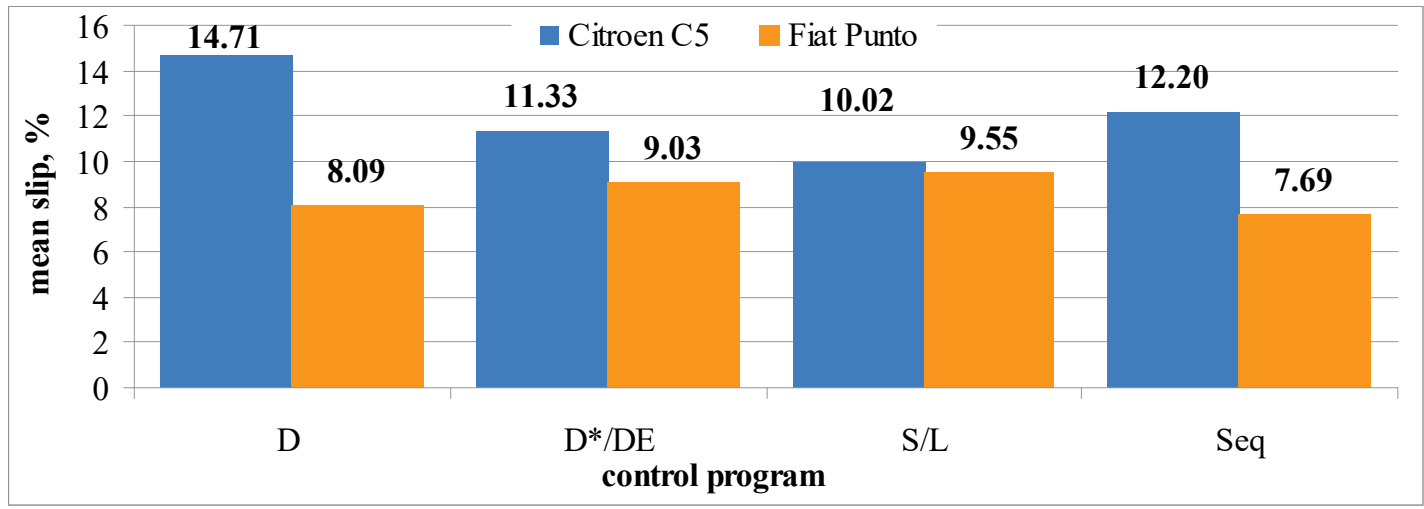

Fig. 13. Mean transmission slip with different control programs (Citroen C5 and Fiat Punto)

Mean transmission slip can assume significantly different values depending on the used control program, namely:

- from $10.02 \%$ for sport driving program S to $14.71 \%$ for standard driving program D in case of Citroen $\mathrm{C} 5$ test vehicle,

- from $7.69 \%$ for sequential gear change program Seq to $9.55 \%$ for dynamic driving program $\mathrm{L}$ in case of Fiat Punto.

\section{Conclusions}

The on-stand experimental tests conducted for urban driving cycles show the effect of both transmission control program and vehicle speed on hydrokinetic torque converter slip. A testdriving cycle which simulated city driving in the range of speeds from 0 to $15 \mathrm{~m} / \mathrm{s}$ has allowed determining converted slip at limited vehicle speeds. The analysis of results has shown that for both test vehicles, there is a certain driving speed or a range of driving speeds, in the scope of which converter slip fades due to mechanical locking of converter turbine and impeller due to engagement of the lock-up clutch. The calculated mean values of converter slip allow for preliminary assessment of control programs. In case of Citroen C5, test vehicle there is a visible tendency of the control programs to allow for larger values of converter slip and a wide range of vehicle speeds during which pump-impeller slip is permitted. Substantial slip values of over $40 \%$ were registered for speeds exceeding $11 \mathrm{~m} / \mathrm{s}$ for the basic transmission control program $\mathrm{D}$. The use of other control programs (for example S) allows to lower the mean slip value from $14.71 \%$ to $10.02 \%$ and earlier engagement of the lock-up clutch at the speed of $7 \mathrm{~m} / \mathrm{s}$.

In the case of Fiat Punto test vehicle equipped with a CVT transmission coupled with a hydrokinetic torque converter, lower converter slip values were noted. The highest noted value of $9.55 \%$ is lower than the lowest mean value noted for the Citroen C5. In the case of Fiat Punto test vehicle, the control programs allow for earlier engagement of the Lock-up clutch. Depending on control program, the mechanical engagement of turbine and impeller occurs in the range of vehicle speeds as small as 6-8 m/s. This results in overall higher drivetrain efficiency. 
Modification of transmission control programs focused on optimizing the range and mode of Lock-up clutch operation and making its engagement point more flexible can therefore improve both economical and dynamic characteristics of vehicle drivetrain.

\section{References}

[1] Bieniek, A., Prażnowski, K., Control and operating conditions and hydrokinetic converter slip in the vehicle's transmission system, IOP Conf Series Materials Science and Engineering, 421, 022003, 2018.

[2] Bieniek, A. Jantos, J., Applying of frictional conditions estimation at thrust force control in continuously variable transmission, JSAE Paper No. 20074543, CVT\& Hybrid Conference, Yokohama 2007.

[3] Bieniek, A., Improvement of emission properties on integrated control of powertrain with CVT and sparking plug engine Combustion Engines, Ecology \& Diagnostic, pp. 25-30, PTNSS, 2007.

[4] Bieniek, A., Jantos, J. Mamala, J., Possibilities of driveability and fuel consumption improvement by advanced control power transmission system in passenger car, Transport (Research Journal of Vilnius Giediminas Technical University and Lithuanian Academy of Scienses), Vol. XXII, No. 4, pp. 247-251, 2007.

[5] Lee, C., Ahn, K., Lee, J. M., Lim, W. S., Slip control strategy for automatic transmission vehicle, KSME International Journal, Vol. 17, No. 4, pp. 521-527, 2003.

[6] McGrath, M., Hemphill, J., Bailey, G., George, P., Swank, M., Krause, T., Torque converters - comfort and fuel economy in tight corners, LUK Symposium, pp. 7-25, 2006.

[7] Middelmann, V., Wagner, U., The torque converter as a system, LUK Symposium, pp. 123156, 2006.

[8] Adibi Asl, H., Lashgarian Azad, N., McPhee, J., Modelling torque converter characteristics in automotive drivelines: lock-up clutch and engine braking simulation, 12PFL-0362 SAE International, 2012.

[9] Koralewski, G., Wrona, R., Autobusy, 6, pp. 800-805, 2017.

[10] Ejiri, E., Analysis of flow in the lock-up clutch of an automotive torque conwerter, JSME International Journal Series B, Vol. 49, No. 1, pp. 131-141, 2006.

[11] https://x-engineer.org.

Manuscript received 26 August 2019; approved for printing 19 December 2019 